\title{
Pavimentação asfáltica: tratamento superficial duplo com capa selante no município de Peixe/TO
}

O Tratamento Superficial é um dos tipos de revestimentos de pavimentos flexíveis, sendo também o mais utilizado pelas suas vantagens em relação aos demais, considerado de baixo custo de mão de obra e de maquinários mais simples para a sua execução, ele também é considerado o mais econômico, principalmente em relação ao Concreto Betuminoso Usinado a Quente (CBUQ). A fim de obter um pavimento de qualidade, devem-se realizar controles de materiais utilizados e serviços realizados na execução do mesmo, buscando uma durabilidade maior do pavimento e menor surgimento de patologias oriundas das mudanças climáticas e devido as falhas corriqueiras no processo executivo, levando em consideração também a qualidade dos materiais utilizados na execução dos mesmos. Sendo assim, foi realizado o acompanhamento e controle de execução do revestimento tipo Tratamento Superficial Duplo no estado do Tocantins no município de Peixe das Ruas 07 e 12 do setor Boa Vista, sendo umas das principais vias de acesso da cidade, com finalidade de verificação da distribuição de emulsão asfáltica e de agregados por área seguindo as normas vigentes do DNIT. Para o controle dos procedimentos e materiais, foi realizado a medição da temperatura do caminhão distribuidor e medidas de taxas de aplicação e espalhamento de ligantes e agregados.

Palavras-chave: Controle de Execução; Ligante Asfáltico; Taxa de Aplicação; Equipamentos.

\section{Asphalt paving: double surface treatment with sealing cover in the municipality of Peixe/TO}

The Surface Treatment is one of the types of flexible floor coverings, being also the most used for its advantages over the others, considered of low cost of labor and of simpler machinery for its execution, it is also considered the most economic, mainly in relation to Hot Machined Bituminous Concrete (CBUQ). In order to obtain a quality floor, controls of materials used and services carried out in its execution must be carried out, seeking greater durability of the pavement and less emergence of pathologies arising from climatic changes and due to common failures in the executive process, leading also take into account the quality of the materials used in their execution. Therefore, monitoring and control of the execution of the Double Surface Treatment type coating was carried out in the state of Tocantins in the municipality of Peixe das Ruas 07 and 12 in the Boa Vista sector, being one of the main access roads in the city, with the purpose of verifying the distribution of asphalt emulsion and aggregates by area following the current DNIT rules. For the control of procedures and materials, the temperature of the distributor truck was measured and measures of application rates and spreading of binders and aggregates.

Keywords: Execution Control; Asphalt Binder; Application Rate; Equipment.

Topic: Engenharia Civil

Reviewed anonymously in the process of blind peer
Received: 09/08/2020

Approved: $\mathbf{2 0 / 1 1 / 2 0 2 0}$
Arthur Richer Camelo Batista

Faculdade Presidente Antônio Carlos, Brasil

http://lattes.cnpq.br/3329175131702505

http://orcid.org/0000-0002-7188-8559

arthuricher.ec@gmail.com

Rafaella Oliveira Guimarães Santos

Faculdade Presidente Antônio Carlos, Brasil

http://lattes.cnpq.br/2006870316534982

rafaellaguimaraes.eng@gmail.com

\section{Referencing this:}

BATISTA, A. R. C.; SANTOS, R. O. G.. Pavimentação asfáltica: tratamento superficial duplo com capa selante no município de Peixe/TO. Engineering Sciences, v.8, n.3, p.39-44, 2020. DOI: http://doi.org/10.6008/CBPC2318-3055.2020.003.0004 


\section{INTRODUÇÃO}

No Brasil o transporte rodoviário é o mais utilizado, tanto para locomover produtos, quanto pessoas. No país há 1,7 milhão de km de estradas, o que amplia a utilização desse transporte. Dentre as estradas que o país possui $12,9 \%$ são pavimentadas e $79,5 \%$ não são pavimentadas. Entre as rodovias $14,8 \%$ são de rodovias estaduais, $78,1 \%$ são rodovias municipais e $7 \%$ são rodovias federais. Dentre essas rodovias podem ser encontradas as rodovias simples e as duplicadas. No país quem coordena o transporte rodoviário no âmbito federal é o Departamento Nacional de Transportes Terrestres (DNIT), que está vinculado ao Ministério dos Transportes. Já no âmbito estadual e municipal, são as secretarias de infraestrutura. No município de Peixe - TO não seria diferente, ainda mais se levarmos em consideração que na região norte $85 \%$ das rodovias estão em situações de regular a péssima, isso sem considerar a porcentagem que ainda faltam ser pavimentadas.

Como a pavimentação asfáltica possui muitas empresas que atuam no ramo, o presente artigo foi realizado a fim de esclarecer o processo executivo e auxiliar para que elas executem de forma mínima aceitável o pavimento. De forma que os pavimentos tenham um aumento significativo na sua durabilidade, de modo que a sua manutenção seja mínima, assim aumentando a garantia dos serviços executados. Os ensaios que foram realizados servem para saber a distribuição das emulsões e de agregados por camada de pavimento. Em determinados ensaios foram analisados parâmetros nas quais devem atender aos critérios de norma estabelecida pelo Departamento de Infraestrutura dos Transportes, sendo possível verificar se o serviço foi realizado de forma aceitável, buscando assim uma durabilidade maior do pavimento e menor surgimento de patologias devido ao processo executivo.

De uma maneira geral, os pavimentos são catalogados em: rígidos e flexíveis. Os que são rígidos são pouco deformáveis, composto principalmente de concreto de cimento, já os que são flexíveis ou não rígidos, são aqueles que as deformações não causam o rompimento (SENÇO, 2011).

De acordo com Panitz (2003), qualquer tipo de pavimento que seja construído com a utilização de agregados, quer sejam naturais ou artificiais, mas que sejam ligados entre si por meio de material asfáltico, independente de qual técnica seja utilizada em sua execução, é chamado de pavimento asfáltico.

Para Balbo (2007) o pavimento é constituído por camadas sobrepostas de materiais diferentes e compactados desde o subleito, adequadas para atender estruturalmente e operacionalmente o tráfego de veículos, de maneira durável e com o mínimo custo possível, considerando todos os serviços de manutenção e regeneração obrigatórios.

Bernucci et al. (2010) definem o revestimento asfáltico como sendo a camada superior designada a resistir diretamente às ações do tráfego de veículos e transmiti-las de forma atenuada às camadas inferiores, impermeabilizar o pavimento, melhorando as condições de rolamento, ficando mais confortáveis e seguros.

Segundo Bernucci et al. (2010), os pavimentos asfálticos são todos aqueles em que o revestimento é composto por uma mistura constituída basicamente de agregados minerais e emulsão que faz as ligações das camadas asfálticas. O revestimento asfáltico pode ser composto por camada de rolamento - em contato 
direto com as rodas dos veículos que por eles trafegam e por camadas intermediárias ou de ligação.

De acordo com o DNIT (2005), os revestimentos betuminosos, ou revestimentos asfálticos, são constituídos por um agrupamento de materiais betuminosos e agregados de diferentes granulometrias, feito por duas maneiras distintas entre si: penetração e mistura. Salienta-se que quando a associação dos materiais betuminosos com os agregados é feita por penetração, está pode ocorrer de forma direta ou invertida. A maneira invertida é quando o revestimento é aplicado por uma ou mais aplicações do material betuminoso que está sendo utilizado, com igual número de espalhamento e compressão das camadas de agregados, cada uma com a granulometria apropriada e determinada no projeto e, conforme o número destas camadas temse o revestimento superficial simples (TSS), duplo (TSD) ou triplo (TST).

Estudo de caso realizado na cidade de Peixe - TO, sendo o foco a execução do pavimento na rua 07 e 12 do setor Boa Vista, dispondo sobre a distribuição de emulsão asfáltica e de agregados por área, com isso foi verificado se seguem as normas 145/2012 e 147/2012 e expondo o processo de execução do pavimento por etapa.

\section{METODOLOGIA}

Neste artigo visa a descrição do pavimento flexível em TSD com capa selante executado em duas ruas (07 e 12) na cidade de Peixe - TO, onde foi realizado o acompanhamento de suas etapas construtivas e verificação da distribuição de emulsão asfáltica nas camadas do pavimento e da distribuição de agregados por camada, com ênfase de constatar se os procedimentos estão de acordo com o preconizado nas normas do DNIT 145/2012 e DNIT 147/2012 que dispõem sobre a distribuição de emulsão asfáltica e sobre o Tratamento Superficial Duplo (TSD).

Também foram apresentados os parâmetros obtidos no controle da execução do Tratamento Superficial Duplo.

$\mathrm{Na}$ etapa de controle da execução, os parâmetros foram verificados de acordo com procedimentos da ES 147 (DNIT, 2012): Taxas de aplicação e de espalhamento de ligante e agregados; Para coleta de amostras do ligante e de agregados, foi utilizada uma bandeja de aço com as dimensões de $40 \times 50 \mathrm{~cm}$ e uma balança para que as amostras sejam pesadas, essa terá uma precisão de $5 \mathrm{~g}$ e capacidade de pesagem de 40 kg; A tolerância admitida na taxa de aplicação de ligante asfáltico é de cerca de 1,5 kg/m²; O número mínimo de determinações por segmento (área inferior a $3.000 \mathrm{~m}^{2}$ ) é de cinco.

\section{RESULTADOS E DISCUSSÃO}

O pavimento asfáltico utilizado para a realização da análise, foi executado no município de Peixe TO, sendo utilizado para análise duas das principais ruas do município que é a rua 07 e a rua 12, na qual a rua 07 tinha um comprimento de 70,78 metros e a rua 12 tinha um comprimento de 640 metros, tendo sua data de avaliação de maio a julho de 2019. 


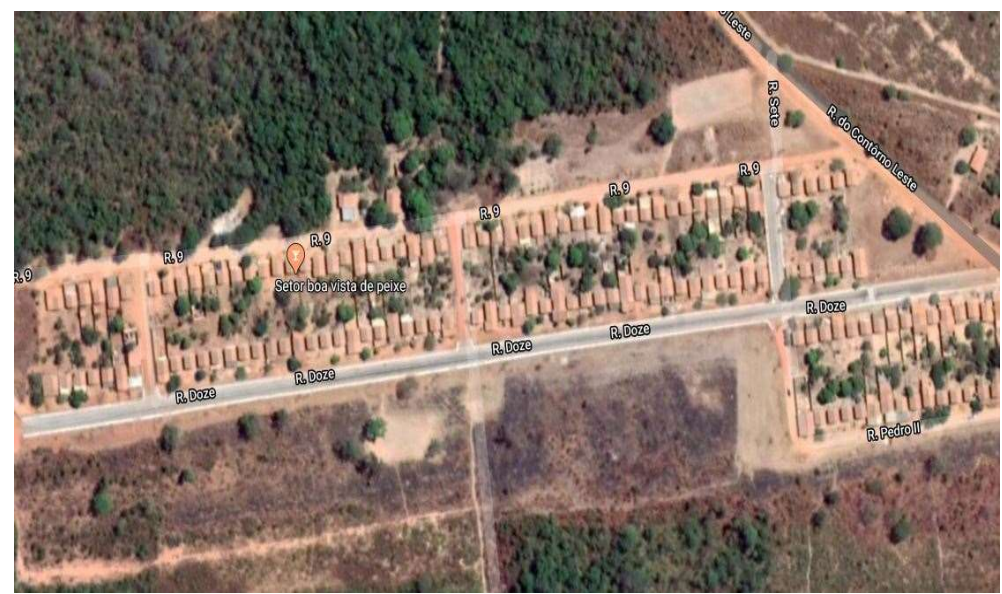

Figura 1: Localização das ruas executadas. Fonte: Google Maps.

O presente documento atesta as condições geotécnicas do material existente nas ruas para as camadas, na obra de pavimentação asfáltica urbana de Peixe - TO, dados obtidos no laboratório da empresa ASR Engenharia, onde foi realizado e executado segundo os parâmetros padrões das normas do DNIT $145 / 2012$ e $147 / 2012$.

A tabela a seguir apresenta os dados obtidos dos ensaios realizados no laboratório, com as especificações das ruas que foram executadas com esses dados a seguir, tendo ênfase nas ruas 07 e 12 que são as ruas analisadas seus padrões de execução conforme as normas do DNIT.

Tabela 1: Resultado TSD.

\begin{tabular}{|c|c|c|c|c|c|c|c|c|c|c|c|c|}
\hline \multirow{3}{*}{$\begin{array}{l}\text { Estaca } \\
\text { ou Km. } \\
\text { Inicial } \\
\end{array}$} & \multirow[b]{3}{*}{ Final } & \multirow{3}{*}{$\begin{array}{l}\text { Serviço } \\
\text { Posição }\end{array}$} & \multirow{3}{*}{$\begin{array}{l}\text { TSD } \\
\text { Rua ou } \\
\text { Avenida } \\
\end{array}$} & \multicolumn{3}{|c|}{ CONTROLE DE TAXAS } & Material & \multicolumn{2}{|l|}{ RR-2C } & \multirow{3}{*}{ Média $\mathrm{It} / \mathrm{m}^{2}$} & \multirow{3}{*}{ Camada } & \multirow{3}{*}{ Periodo } \\
\hline & & & & \multicolumn{2}{|c|}{ Bandeja } & \multicolumn{2}{|l|}{ Peso } & \multirow{2}{*}{\begin{tabular}{|l|} 
Taxa \\
$\mathrm{It} / \mathrm{m}^{2}$
\end{tabular}} & \multirow{2}{*}{ oC } & & & \\
\hline & & & & Área & Tara g. & Bruto g. & Liquido g. & & & & & \\
\hline 0 & \multirow{2}{*}{$\frac{0}{0}$} & LD & \multirow{2}{*}{ Rua 07} & 0,0575 & 1,339 & 1,427 & 0,088 & 1,530 & \multirow{2}{*}{65} & \multirow{2}{*}{1,252} & \multirow{2}{*}{$1 \underline{a}$} & \multirow{2}{*}{ Mês/06 } \\
\hline 0 & & LE & & 0,0575 & 1,425 & 1,481 & 0,056 & 0,974 & & & & \\
\hline 0 & 0 & LD & \multirow{2}{*}{ Rua 07} & 0,0575 & 1,350 & 1,405 & 0,055 & 0,957 & \multirow{2}{*}{65} & \multirow{2}{*}{0,957} & \multirow{2}{*}{$2^{\underline{a}}$} & \multirow{2}{*}{ Mês/06 } \\
\hline 0 & 0 & LE & & 0,0575 & 1,405 & 1,460 & 0,055 & 0,957 & & & & \\
\hline 0 & 0 & LD & \multirow{2}{*}{ Rua 07} & 0,0575 & 1,380 & 1,434 & 0,054 & 0,939 & \multirow{2}{*}{65} & 0.974 & 3a & Mês/06 \\
\hline 0 & 0 & LE & & 0,0575 & 1,434 & 1,492 & 0,058 & 1,009 & & דיל & & 年 \\
\hline 0 & 0 & LD & Rua 12 & 0,0575 & 1,339 & 1,427 & 0,088 & 1,530 & 65 & 1252 & $1 \underline{a}$ & Mês/06 \\
\hline 0 & 0 & LE & The 25 & 0,0575 & 1,425 & 1,481 & 0,056 & 0,974 & 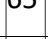 & $1,2 उ 2$ & ${ }^{1-}$ & |vies/00 \\
\hline 0 & 0 & LD & Rua 12 & 0,0575 & 1,350 & 1,405 & 0,055 & 0,957 & 65 & 0957 & $\partial \underline{a}$ & Mês/06 \\
\hline 0 & 0 & LE & Nua 12 & 0,0575 & 1,405 & 1,460 & 0,055 & 0,957 & (כ) & וכבות & $<-$ & |vies/00 \\
\hline 0 & 0 & LD & Rua 12 & 0,0575 & 1,380 & 1,434 & 0,054 & 0,939 & -65 & 0.974 & 3a & Mês/06 \\
\hline 0 & 0 & LE & Kud 12 & 0,0575 & 1,434 & 1,492 & 0,058 & 1,009 & 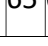 & 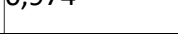 & rar & 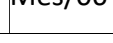 \\
\hline CONTR & DLE DE & AXAS DO & S AGREGA & & & & & & & & & \\
\hline Estaca & u Km. & Posicão & Rua ou & Bandeja & & Peso & & Taxa & oc & Média & Camada & Data \\
\hline Inicial & Final & PUડ & Avenida & Área & Tara & Bruto & Liquido & $\mathrm{It} / \mathrm{m}^{2}$ & & $\mathrm{Kg} / \mathrm{m}^{2}$ & Camiana & Dalda \\
\hline 0 & 0 & LD & & 0,0880 & 1,732 & 3,450 & 1,718 & 19,523 & & & & \\
\hline '́ & 0 & LE & Rua 07 & 0,0880 & 1,734 & 3,400 & 1,666 & 18,932 & & 20,227 & Brita 1 & Mês/06 \\
\hline 0 & 0 & LD & & 0,0880 & 1,732 & 2,770 & 1,038 & 11,795 & & & & \\
\hline 0 & 0 & LE & Rua 07 & 0,0880 & 1,734 & 2,700 & 0,966 & 10,977 & & 11,386 & Brita 0 & Mês/06 \\
\hline 0 & 0 & LD & Rua 07 & 0,0880 & 1,732 & 2,150 & 0,418 & 4,750 & & 5,136 & Po & Mês/06 \\
\hline 0 & 0 & LE & Nuta & 0,0880 & 1,734 & 2,220 & 0,486 & 5,523 & & 0,130 & ro & |lvies/00 \\
\hline 0 & 20 & LD & Rua 12 & 0,0880 & 1,732 & 3,450 & 1,718 & 19,523 & & 20,227 & Brita 1 & Mês/06 \\
\hline 0 & 20 & LE & Nud IL & 0,0880 & 1,734 & 3,400 & 1,666 & 18,932 & & $<0,2<1$ & & Dives \\
\hline 0 & 20 & LD & 12 & 0,0880 & 1,732 & 2,770 & 1,038 & 11,795 & & 11,386 & Brita 0 & Mês/06 \\
\hline 0 & 20 & LE & Nua 12 & 0,0880 & 1,734 & 2,700 & 0,966 & 10,977 & & & Dima & \\
\hline 0 & 20 & LD & Rua 12 & 0,0880 & 1,732 & 2,150 & 0,418 & 4,750 & & 5,136 & Po & Mês/06 \\
\hline 0 & 20 & LE & Nua 12 & 0,0880 & 1,734 & 2,220 & 0,486 & 5,523 & & & & \\
\hline
\end{tabular}

Os resultados obtidos pelo relatório de execução foram comparados com os parâmetros padrões 
constituintes nas normas do DNIT, na qual o primeiro parâmetro analisado foi se o ligante asfáltico não foi distribuído numa temperatura inferior ou igual a dez graus Celsius, contudo as ruas sete e doze foram distribuídos seus ligantes numa temperatura de sessenta e cinco graus. Tendo em vista que só podem ser empregados os seguintes ligantes dependendo da indicação do projeto cimentos asfálticos CAP 150/200 e emulsões asfálticas tipo RR-2C.

Outro aspecto importante analisado com a Especificação de Serviço 147 (DNIT, 2012), foram as quantidades ou taxas de aplicação de ligante asfáltico e de espalhamento de agregados que devem ser fixadas no projeto e ajustadas no campo. Valores recomendados podem ser observados na Tabela 3. A referida norma recomenda de maneira geral as taxas de aplicação apresentadas na Tabela 2.

Tabela 2: Taxas de aplicação.

\begin{tabular}{|l|l|l|}
\hline Camada & Ligante & Agregado \\
\hline 1 a & 1,2 a $1,8 \mathrm{I} \mathrm{m}^{2}$ & 20 a $25 \mathrm{~kg} / \mathrm{m}^{2}$ \\
\hline 2a & 0,8 a $1,2 \mathrm{I} \mathrm{m}^{2}$ & 10 a $12 \mathrm{~kg} / \mathrm{m}^{2}$ \\
\hline
\end{tabular}

Fonte: ES 147 (DNIT, 2012).

Todavia as taxas de aplicação são calculadas pela seguinte fórmula:

$$
T=\frac{P 2-P 1}{A}
$$

Tabela 3: Taxas de aplicação das ruas 07 e 12.

\begin{tabular}{|l|l|l|l|}
\hline Rua & Camada & Ligante & Agregado \\
\hline 07 & $1 \underline{a}$ & $1,252 I \mathrm{~m}^{2}$ & $20,227 \mathrm{~kg} / \mathrm{m}^{2}$ \\
\hline 07 & $2^{\underline{a}}$ & $0,957 I \mathrm{~m}^{2}$ & $11,386 \mathrm{~kg} / \mathrm{m}^{2}$ \\
\hline 12 & $1 \underline{a}$ & $1,2521 \mathrm{~m}^{2}$ & $20,227 \mathrm{~kg} / \mathrm{m}^{2}$ \\
\hline 12 & $2 \underline{a}$ & $0,957 / \mathrm{m}^{2}$ & $11,386 \mathrm{~kg} / \mathrm{m}^{2}$ \\
\hline
\end{tabular}

Com os dados obtidos da ASR Engenharia do resultado da execução do TSD, exposto na Tabela 1, tanto a rua 07 quanto a 12 estão dentro do intervalo recomendado das taxas de aplicação de ligante asfáltico e de espalhamento de agregados que devem ser fixadas no projeto e ajustadas no campo, recomendações da norma do DNIT 147/2012, pois o intervalo das taxas de aplicação de ligante asfáltico da primeira camada é de 1,2 a 1,8 I m² e das ruas 07 e 12 corresponderam a 1,252 I $\mathrm{m}^{2}$, e da segunda camada o intervalo é de 0,8 a 1,2 $\mathrm{I} \mathrm{m}^{2}$ e das ruas 07 e 12 corresponderam a 0,957 I $\mathrm{m}^{2}$.

Já o intervalo da primeira camada do espalhamento de agregados é de 20 a $25 \mathrm{~kg} / \mathrm{m}^{2}$ e das ruas 07 e 12 foram 20,227 kg/m², e da segunda camada é de 10 a $12 \mathrm{~kg} / \mathrm{m}^{2}$ e das ruas 07 e 12 foram 11,386 kg/m². No entanto todas as fases da obra de pavimentação das ruas 07 e 12 de Peixe - TO foram atreladas as normas do DNIT visando sempre obedecer aos padrões estabelecidos de execução.

Voltando a frisar que os dados analisados e comparados com as normas pertinentes do DNIT, foram todos obtidos através dos laboratórios da ASR Engenharia, pois ela foi a responsável pela obra apresentada no presente artigo.

\section{CONCLUSÕES}

O acompanhamento das obras de pavimentação no município de Peixe - TO das ruas 07 e 12 , não 
teve por objetivo realizar testes, e sim fazer a verificação dos resultados obtidos para saber se enquadra nos valores impostos pela norma do DNIT, e também observando no acompanhamento das obras se seguiram os requisitos técnicos de qualidade de um projeto adequado, e cumprindo sempre com as normas pertinentes, evitando assim patologias e negligências de execução.

Os resultados mostraram que o ensaio realizado pela empresa ASR Engenharia, obteve dados que estão dentro do intervalo das normas do DNIT, e vale frisar que toda a execução desde o laboratório até a realização do pavimento foi executada sobre responsabilidade da empresa ASR Engenharia, baseado nas normas de pavimentação garantindo assim que o pavimento possua flexibilidade, estabilidade, durabilidade e resistência.

\section{REFERÊNCIAS}

BALBO, J. T.. Pavimentação asfáltica: materiais, projeto e restauração. São Paulo: Oficina de Textos, 2007.

BERNUCCI, L. B.; MOTTA, L. M. G.; CERATTI, J. A. P.; SOARES, J. B.. Pavimentação Asfáltica: formação básica para engenheiros. Terceira reimpressão Rio de Janeiro: Petrobras, 2010.

DNIT. Departamento Nacional de Infraestrutura de Transportes. NORMA DNIT 145/2012 - ES: Pavimentação. Pintura de ligação com ligante asfáltico. Especificação de serviço. DNIT, 2012.
DNIT. Departamento Nacional de Infraestrutura de Transportes. NORMA DNIT 147/2012 - ES: Pavimentação Asfáltica. Tratamento Superficial Duplo. Especificação de serviço. DNIT, 2012.

PANITZ, M. A.. Dicionário Técnico: Português-Inglês. Porto Alegre: EDIPUCRS, 2003.

SENÇO, W.. Manual de Técnicas de Pavimentação. 2 ed. São Paulo: Pini, 2001.

A CBPC - Companhia Brasileira de Produção Científica (CNPJ: 11.221.422/0001-03) detém os direitos materiais desta publicação. Os direitos referem-se à publicação do trabalho em qualquer parte do mundo, incluindo os direitos às renovações, expansões e disseminações da contribuição, bem como outros direitos subsidiários. Todos os trabalhos publicados eletronicamente poderão posteriormente ser publicados em coletâneas impressas sob coordenação da Sustenere Publishing, da Companhia Brasileira de Produção Científica e seus parceiros autorizados. Os (as) autores (as) preservam os direitos autorais, mas não têm permissão para a publicação da contribuição em outro meio, impresso ou digital, em português ou em tradução. 